\title{
The Analysis of NEEQ in China
}

\author{
Yusi Li \\ Economics and Finance, the University of International Business and Economics, Beijing, 100029, \\ China \\ yusi.li@yahoo.com
}

\begin{abstract}
The year 2015 has witnessed the booming of NEEQ (National Equities Exchange and Quotations). The advantages of listing in the NEEQ, such as the policy support and the improvement of stock liquidity have stimulated the enthusiasm of enterprises in a large extent. Driven by different parties, the NEEQ has obtained the remarkable results. The number of the listed companies and market capitalization volume are experiencing the most rapid growth since the NEEQ has been established.
\end{abstract}

Keywords: NEEQ; Liquidity; Layer-management; Transfer System.

\section{Introduction}

The NEEQ (National Equities Exchange and Quotations), or called OTC (over-the-counter market) is a new capital market which offers financial services to the innovation enterprises in the start-up period or growth period and provides the equity transfer services, the exit strategies of mergers and acquisitions to entrepreneurial venture capital outside the main board and the second-board market[6]. The NEEQ trades typically through OTC trading electronic counter, with Securities Companies as intermediary. In our country, NEEQ is also called Agency Share Transfer System, divided into the new three board market and old three board market. The NEEQ is established in the July 2001 in order to solve the historical problems left by the two networks STAQ and NET, the equity transfer problems related to delisting companies of main board. On the other hand, established in January, 2016, the NEEQ is the transfer pilot program for Private co., LTD in the Zhongguancun Science \& Technology Zone to enter the Agency Share Transfer System. Because the listed companies in this new capital market all are high-tech enterprises varied from the delisting enterprises in the old transfer system or in the old STAQ and NET system, so it is called the new three board market.

From the establishment of the Agency Share Transfer System for the Private co., LTD in Zhongguancun Science \& Technology Zone to enter in 2006 to the market expansion in 2012, and to the establishment of market maker system, the NEEQ has shown several times of development trend of the blowout. Statistics has shown that the NEEQ is developed in fast speed in 2015. Accompanied by coming out of the hierarchical scheme for the listed companies in national stock transfer system (draft) ", the NEEQ has met the new opportunities to develop. However, the reality has shown that the NEEQ is still in the initial development period and faces many challenges compared with other mature OTC market internationally.

The rest of this article structure arrangement is as follows: the second chapter reviews the relevant literatures; the third chapter analyst the development condition of the NEEQ in 2015; the forth chapter concludes the new development opportunity of NEEQ in the future; the fifth concludes the challenges of the NEEQ in the future; the final chapter makes a conclusion.

\section{The development condition of NEEQ}

\section{1 market profile}

The year 2015 has witnessed the fast development of NEEQ market. Up to the December 31st, 2015 , the total equity increased by $349.53 \%$ to 2959.51 billion shares, as shown in figure 1 ; the total market capitalization increased by $435.44 \%$ to 24584.42 billion Yuan, as shown in figure2; the number of listed companies in the NEEQ increased by $226.27 \%$ to 5129 , compared with that in 2014 , as shown in figure 3; average profit rate increased by $33.90 \%$ to 47.23 times, as shown in figure 4 [8]. 

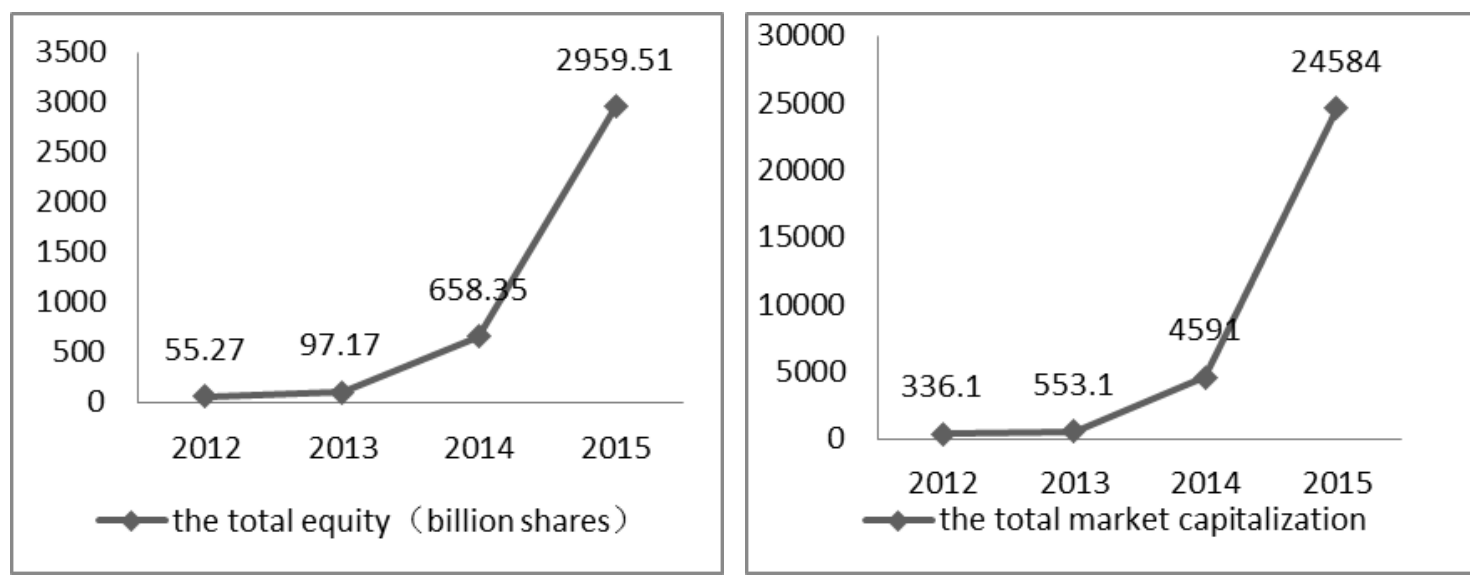

Figure 1 The total equity

Figure 2 The total market capitalization

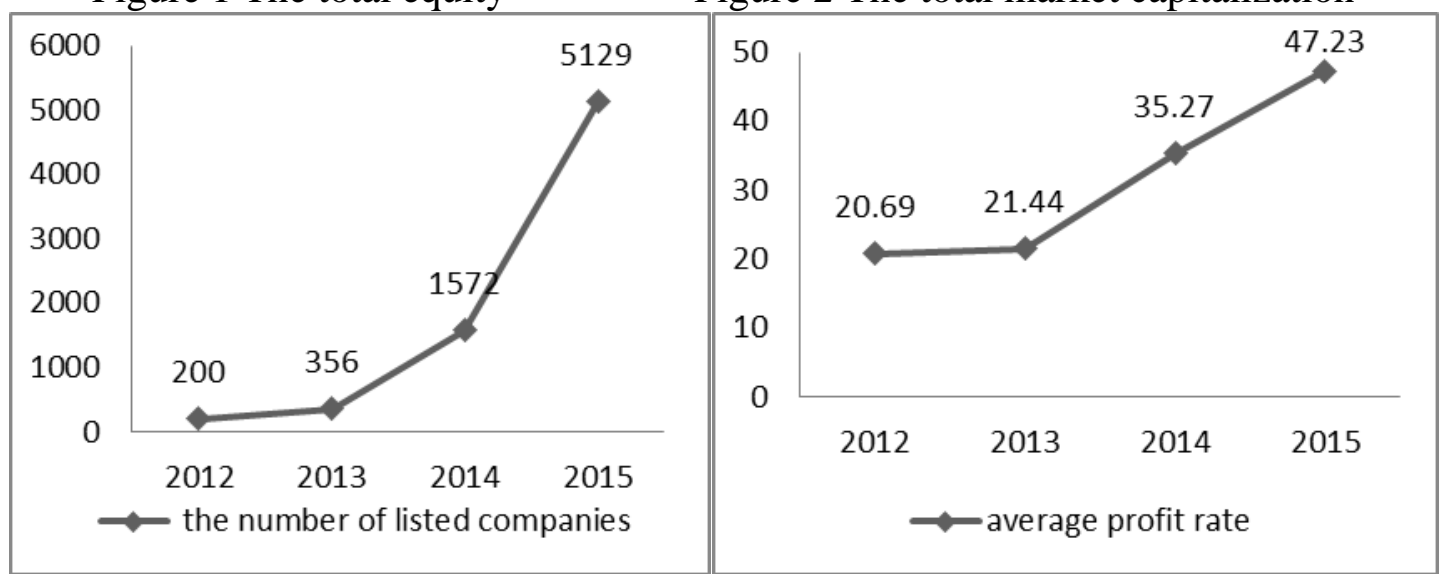

Figure 3 The number of listed companies

Figure 4 Average profit rate

In addition, private placement market is also booming, up to December 31st, 2015, the accumulative number of private placement companies increased by 2236 to 2565 , compared with that of 2014. These companies have raised 1216.17 billion Yuan by the way of private placement in 2015, the number of which is 132.09 billion Yuan. The change of the NEEQ is noticeable.

\subsection{Geographical distribution}

NEEQ is established on January 23rd, 2006, when the Private co., LTD in Beijing Zhongguancun Science \& Technology Zone entered the Agency Share Transfer System. In the end of 2013, NEEQ push through the limitation of national Science \& Technology Zone and expanded to all the eligible companies. Beijing, Shanghai, Guangzhou, Jiangsu and Zhejiang area, the cluster of innovation, with the addition of the advantages of territory and resources will be the collection location of small business and micro-enterprises of high technology, as shown in figure5. Since the economics of central and western regions is not active due to the limitation of territory and resources, the number of listed companies is significantly different.

\subsection{Industry distribution}

In the industry view, among the listed companies in NEEQ in 2015, the manufacturing industry ranks the first by $1247(35 \%)$, and IT ranks the second by 546 by $15 \%$, which amount to occupied more than half of the companies in the NEEQ [8]. The listed companies in the NEEQ are mainly in manufacturing industry and IT all the time and this trend will continue. Meanwhile, the proportion of listed internet companies has increased, by the policy guidance of "Public entrepreneurship and innovation", the internet companies will usher in the new wave of development. The number of new listed internet companies reached 50 just in December 2015 [8]. The NEEQ has become the first choice of the internet companies to enter the capital market through the inclusive market mechanism and marketization operation pattern. In addition, statistics shows that in 2015 the newly listed companies in cultural media industry added 87 , construction material industry added 69 , and the real estate industry added 26, which still have the distance compared to the high technique companies. The financial companies added 93, accounting for 3\%, and some futures, lease and microcredit financial companies have also entered the NEEQ. In the long term, the strengthen of market 
supervision and the regulation of trading are beneficial to improve the number of great listed companies and operation quality, as well as accelerate the healthy development of the market.

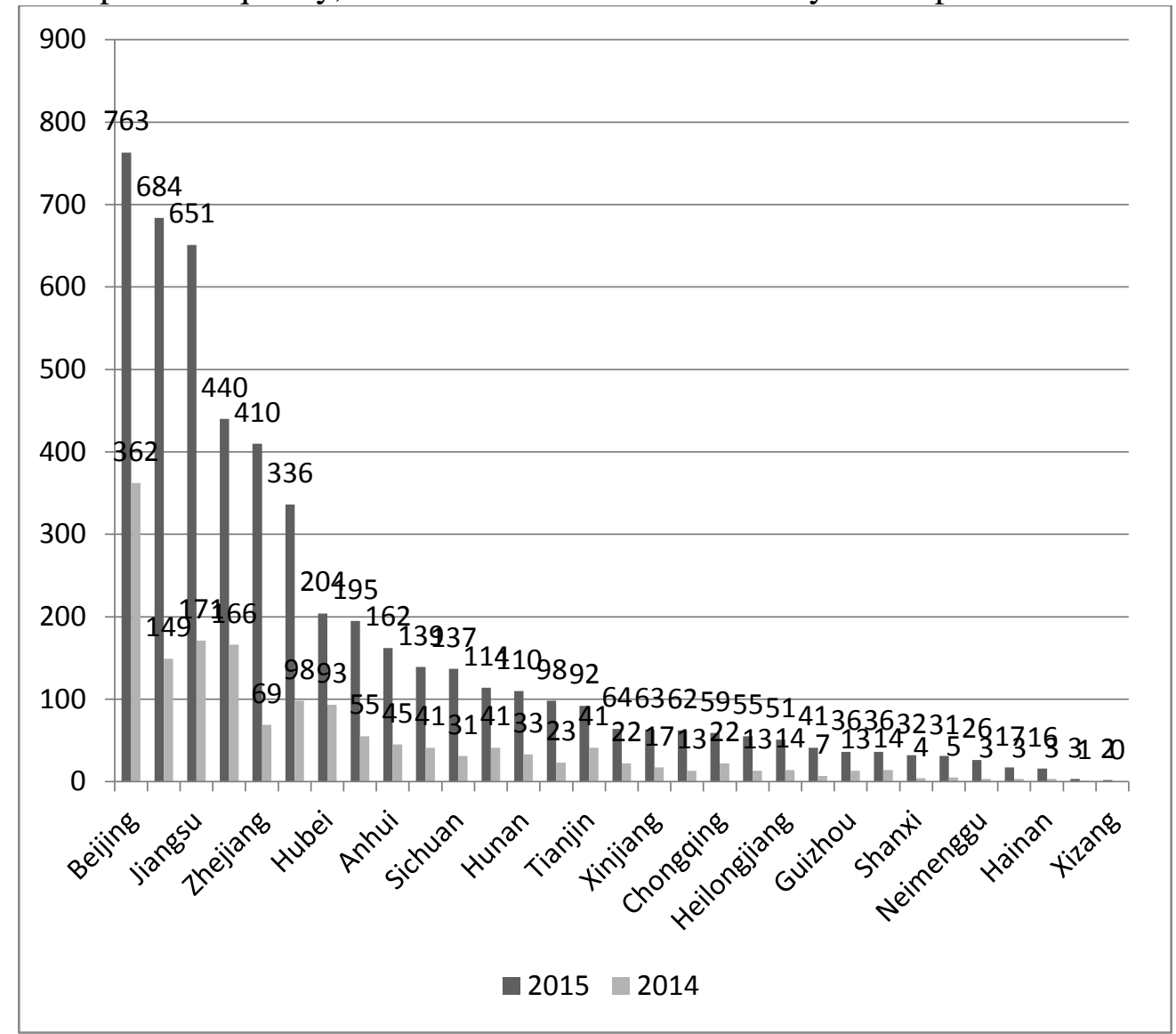

Figure 5 Geographical distribution of listed companies in NEEQ

\section{The development opportunity of NEEQ}

\subsection{The internet companies have become the new Growth Points}

Since the latter half of the year 2015, the internet companies have become the favorite of NEEQ. Plenty of high quality underlying or well-known internet companies entered the NEEQ, and there will be more and more internet companies in the NEEQ in the future. The internet companies need large amount of fund to support, so that entering the NEEQ benefits the further development of the internet companies.

In the future, by the policy guidance of "Public entrepreneurship and innovation", the internet companies will usher in the new wave of development. On the other hand, the NEEQ has become the first choice of the internet companies to enter the capital market through the inclusive market mechanism and marketization operation pattern. In the long term, the strengthen of market supervision and the regulation of trading are beneficial to improve the number of great listed companies and operation quality, as well as accelerate the healthy development of the market.

\subsection{Share financing assist the private placement}

The NEEQ has raised 1216.17 billion Yuan in 2015, surpassing which of growth enterprises market is 60 billion Yuan. The three rounds private placement of CSM Group raised 90.37 billion Yuan in the first half of the year 2015, which broke the history. On the September 9th, CSM Group started another new round private placement. In this round, the CSM Group calculated the issue price to 27 Yuan per share and total financing no more than 300 billion Yuan. Such large scale of the private placement never appeared in the history of NEEQ. The reason for such quick improvement of private placement is that the simpler approval links make the more tolerant financing environment. It takes a company less than one month from putting forward the private placement plan to bringing it into force, compared to 180 days in the main board market, which save the time in a large extent. 


\subsection{Market Maker accelerate the further develop of the NEEQ}

Since the market maker system was introduced in August 2014, the NEEQ met the new growth point. The stock of the listed companies can be transferred by means of market maker transfer, negotiating transfer, or price competing. The market maker system is a kind of security transaction system through the intermediary of market maker. The market maker offers the two-way price to the market, and investors choose whether to close the deal in terms of the price. In the traditional market maker system, the delegation of investors is not made the deal directly. The real meaning of the market maker is to offer the reasonable price fluctuation range of the security through the professional study and to do the related trading activities. It can maintain the liquidity of stock, make investors know the stock and give support to the company. A great market maker would not try to make the price of stock too high or too low. It would not make a large amount of money from prices fluctuation. The goal of the market maker is to offer the reasonable pricing service to the companies and rational investment service to the investors. This kind of market makers is what we need and is the significant part of the Chinese capital market in the developing process.

Up to the end of December 2015, the number of the companies with market maker is 4809 . As the hierarchical system in NEEQ will be introduced soon, the market maker will have new development opportunity in the NEEQ. On the other hand, the further improvement of the market maker system also make the NEEQ have the new growth point.

\section{The challenge of NEEQ}

\section{1 light trading volumes and poor liquidity}

The equity liquidity can be estimated through four Indicators: the first is turnover rate, the second is monthly turnover, the third is the price fluctuation of stock, and the forth is price and volume. The turnover rate of NEEQ in 2015 is $53.88 \%$, surpassing $19.67 \%$ in 2014 . The reasons for the liquidity of the stock in NEEQ in 2015 exceeds that in 2014 are as follows. First, a larger amount of money was put into the market. Second, the market maker system was introduced. Third, the investors are becoming more and more interested in NEEQ [3].

However, up to the December 31st, among the 5129 companies, just 2565 companies issued the stock, which means at least 2500 companies had no trade. This phenomenon is not accordance with the large scale of NEEQ. It is clear that light trading volumes and poor liquidity are still the main problems urgent to be solved.

The reasons for trading volumes and poor liquidity are as follows. To commence, there are plenty of differences between the NEEQ market and the main board market. The object of many companies is to have a platform to show their stock right, rather than financing a large amount of money in short time or current transaction. Apart from the financing function, brand communication and advertising effect are also what they value. In addition, the pause and reboot of IPO, the force out of PE and VC in NEEQ, the poor implement of hierarchical system and price competing system are also the reasons of light trading volumes and poor liquidity [7]. Finally, in the current competitive system of market maker, some market makers pursued the trading volumes in blind, which is not accordance with the object of the introduction of the market maker and improvement of liquidity.

The poor liquidity of NEEQ has seriously influenced the development of NEEQ. The poor liquidity and function value affect the behavior of institution directly. In the view of the overall situation, although the scale of the private placement is expanding all the time, the enthusiasm of institutions to participate the private placement of the companies is floating. Statistics shows that the amount of money for $\mathrm{VC}$ and $\mathrm{PE}$ to participate the private placement is about $20 \%$ in 2015 , which had the decrease tendency in the second quarter [3].

As a result, in order to solve the poor liquidity problem, we have a lot to do: expand the applicable range of the market maker, improve the liquidity of equity right, accelerate the speed of information disclosure, as well as put the hierarchical system and price competing system into practice.

\subsection{The hierarchical system need to be put into practice}

Up to now, the listed companies have been more than 4000. The market generally predicts that the number of listed companies in NEEQ will reach to one million and the scale of listed company has 
exceeded 2780 in Shanghai and Shenzhen A stock market. But the companies in the NEEQ are of different quality, including the companies pulled out from IPO and the large unprofitable companies [7]. According to the statistics from the first half of 2015, among the listed companies which have disclose their performance, the number of the unprofitable ones is 906 and the number of the companies whose net profit decreased year-on-year is 1083. And the most unprofitable company loosed 1.04 billion Yuan. It is clear that the number of listed companies increased in a large extent, the financial characteristic and liquidity characteristic of the listed companies are of significant difference. These factors show that the NEEQ needs the hierarchical system. On the other hand, the burden of regulators increased day by day, the requirement from the market environment to the investors increased and the signal market can't satisfy the development of the companies. These subjective factors also call for the introduction of the hierarchical system.

On November 24th 2015, the hierarchical plan of national Agency Share Transfer System (request for proposal) was introduced. The proposal put forward to imply the hierarchical system in the NEEQ, which is divided into base layer and innovation layer [8]. The companies which can be put into the innovation layer are of three kinds: The first one is white horse companies, the net profits of which in two years reach more than 20 million; the second one is black horse companies, the average revenues of which reach 40 million and the gross rate of the second successive two years should exceed 50\%; the third one is pageant, which makes 6 billion market capitalization by trading, the product of price and capital stock exceeds 6 billion and has more than 6 market makers. After the hierarchy, those which are put into the higher layer would be supervised more seriously, as well as enter the pilot of put down investment threshold and completing price formation mechanism preferentially. This hierarchical system is similar to that of NASDAQ.

Looking back to the development history of NASDAQ, it has developed to the leading comprehensive securities exchange, through the forty-year baptism of the capital market. Compared with NASDAQ, the development history of NEEQ is short, but the gross rate of the number of the listed companies increase quickly, which is similar to the condition of the first hierarchical of NASDAQ in 1982[5]. What's more, they have the similarity of development stage, path and direction, so that using the experience of the hierarchical system in NASDAQ timely and effectively has the significant turning-point for the hierarchical system in NEEQ to be perfect.

\subsection{The transfer system needs to be perfect further}

Because of the limitation of the distinguish difference between the listing standard of NEEQ and GEM, the transfer from NEEQ to GEM is not smooth all the time. Up to now there are three ways to transfer: the first one is transfer through IPO, the second one is through acquisition, and the third is through back-door listing company. Statistics shows that from 2007 to now, the transfer in the NEEQ just occurred 11 times, which is less effective. And the average time from the IPO application day to listing successfully among these 11 companies is 2.19 years [4]. The hazing technology company (53.390, 0.15, and 0.28\%) put forward the IPO application on March 25th, 2010, but it is not listed until June 10th, costing 5.19 year totally [4]. It is clear that the transfer system of NEEQ is still in the initial developing period.

However, the poor transfer system has limited the development of NEEQ seriously. The developed degree of the capital market depends on the different hierarchical structures and the probability of transfer in the different hierarchical structures. According to the development condition of the NEEQ, it is of great significance to develop the two-way transfer system between NEEQ and A share market. To commence, we should solve the contradiction of the supply and demand of fund and relax the difficulty for middle and small companies to financing. In addition, forced descending system can avoid the marketing hype and increase the stability of capital market. Finally, the two-way transfer system can make management of the company attach great importance to the built-in control and perfect the corporate government mechanism.

The proposal introduced on November 2015 put forward that we need to push out the pilot of the listed companies in the NEEQ transfer to the GEM. The establishment of the transfer system from NEEQ to GEM would make NEEQ become the bridge from GEM and district market. And through breaking the barrier between NEEQ and GEM, some of the funds can be circulated through markets. 
In conclusion, grasping the opportunity of the pilot of transfer and take example of the thorough transfer system in OTC market will benefit the future development of the transfer system of NEEQ.

\section{Literature References}

Over-the-counter market is the significant part in the mature multi-level capital market. The mature Over-the-counter markets around the world include NASDAQ in the America, JASDAQ in the Japan and the counter market in Taiwan. Up to now, the capital market in our country is in the stage of developing the multi-level and has developed various trading platforms, including main-Board Market, small and medium enterprises board, growth enterprises market, national equities exchange and quotations and property dealing market, etc. Depended on the Shanghai and Shenzhen exchange, the main-Board Market, small and medium enterprises board and growth enterprises market have mainly developed the national market, meanwhile, developing the nationwide national equities exchange and quotations and property dealing market is the task during the "Twelfth Five-year Plan" period.

The NEEQ is the Agency Share Transfer System for the Private co., LTD in Zhongguancun Science \& Technology Zone in the beginning. Xiong Sanlu (2012) compared the NASDAQ in the America with NEEQ, reviewed the developing history of NEEQ and put forwarded that NEEQ had promoted the development of small and medium-sized high-tech enterprises and has perfected the system of the venture capital exit [6]. However, Tian Juanjuan (2014) analyzed the particularity of liquidity risk management in the angle of trading way and trading regulation, fitted liquidity change rate sequence of the samples and concluded that the liquidity of the NEEQ was lower than any other securities markets, the stability of the liquidity risk value was poor and the risk characteristics is significant [1]. Pan Xiangjun (2011) compared the transfer mechanism in our country with that of the international primary OTC markets and concluded that NEEQ is the important part of the OCT and the fundamental of the multi-level capital market in our country. What's more, the transfer mechanism of NEEQ has the vital function to optimize the capital market [2]. Deng Shaohong (2015) analyzed the hierarchical system of the international primary OTC and put forwarded that hierarchical system of NEEQ was still in the initial development period and still needed to be optimized. It is clear that there are still many challenges in the development of the NEEQ [8].

The 2015 annals of NEEQ Statistics show that the NEEQ has developed fast in the year 2015. This article will use the latest data, combined with the country's most recent policy to analyze the development present situation, development opportunity and challenges of NEEQ.

\section{Summary}

Looking back to the development history of NEEQ, from the establishment of the Agency Share Transfer System for the Private co., LTD in Zhongguancun Science \& Technology Zone to enter in 2006 to the market expansion in 2012, and to the establishment of market maker system, the NEEQ has shown several times of development trend of the blowout. Statistics has shown that the NEEQ is developed in fast speed in 2015. Accompanied by the introduction of the hierarchical plan of national Agency Share Transfer System (request for proposal) on November 24th 2015, the NEEQ is predicted to develop in the fast speed in the future. The innovation companies such like internet companies are willing to become the new growth point in the future.

However, compared to the perfect OTC market all around the world, such as NASDAQ, JASDAQ and TAISDAQ, the NEEQ is still in the initial developing period and the regulations are not perfect. Only if we improve the liquidity, implement the completing price system, complete the hierarchical governance, perfect the market maker system and transfer system, can the NEEQ develop sound in long term. 


\section{References}

[1] Tian Juanjuan. The Liquidity Dangerous of NEEQ after Market Expansion [J]. Financial Forum, 2014, (11): 22-28.

[2] Pan Yujun. Our Country NEEQ Transfer Mechanism and the Research on the Reference to the International Experience [J]. Theoretical research, 2011 (7):106-107.

[3] Huang Yangyang, Remark on Equity Liquidity of NEEQ China Economic \& Trade [J]. Herald National Bureau of Economic Research, 2015, (32): 12-19

[4] Xiao Qing, Deep Research on Transfer Instance in NEEQ [J/OL]. http://www.qianzhan.com/analyst/detail/340/140314-8d489958.html, 2014-03-14

[5] Zhang Jie, Comparison between the Chinese and American Hierarchical Capital Market and Inspiration for the Development of NEEQ [J]. Commercial Times, 2013, (30): 78-79

[6] Xiong Sanlu, the Analyst of the Condition of NEEQ and Development Suggestions [J]. Science and Technology Management Research, 2012, (21): 34-37

[7] Shi Suning, the System of NEEQ Has Been Perfect the Liquidity Financing is the Weaknesses [R]. Shanghai: China Venture Research, 2015, 1-10

[8] Deng Shaohong, NEEQ Attract More Money the Trend of Polarization is Obvious [R]. Shanghai: China Venture Research, 2015, (32): 12-19. 